\begin{tabular}{|c|c|}
\hline & $\begin{array}{l}\text { International Journal of Trend in Scientific } \\
\text { Research and Development (IJTSRD) }\end{array}$ \\
\hline 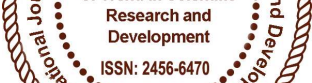 & International Open Access Journal \\
\hline 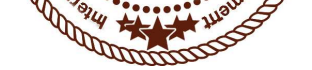 & ISSN No: 2456 - 6470 | www.ijtsrd.com | Volume - 2 | Issue - 2 \\
\hline
\end{tabular}

\title{
A DC-DC Converter with High Voltage Gain and Two Input Boost Stages for Solar Applications
}

\author{
K HimaVani \\ Department of EEE, Amrita Sai Institute of Science \& \\ Technology, Paritala, Krishna District, \\ Andhra Pradesh, India
}

\author{
Ch Chinna Veeraiah \\ Department of EEE, Amrita Sai Institute of Science \& \\ Technology, Paritala, Krishna District, \\ Andhra Pradesh, India
}

\begin{abstract}
An efficient dc boost converter with two input boost stages and high voltage gain is proposed for solar applications. The suggested topologies can be used as multiport converters and draw continuous current from two input sources. Continuous current can also be drawn from a single source in an interleaved manner. This can be used in solar farms. The proposed converters can easily achieve a gain of 20 while benefiting from a continuous input current. Such a converter can individually link a PV panel to a $400-\mathrm{V}$ dc bus. This proposed work is carried out using MATLAB/Simulink platform.
\end{abstract}

Keywords: Photovoltaic, MPPT, Voltage Multiplier, Fuel Cells

\section{INTRODUCTION}

WITH the increased penetration of renewable energy sources and energy storage, high-voltage-gain dc-dc power electronic converters find increased applications in green energy systems. They can be used to interface low voltage sources like fuel cells, photovoltaic (PV) panels, batteries, etc., to the $400-\mathrm{V}$ bus in a dc microgrid system (see Fig. 1) [1]-[3]. They also find applications in different types of electronic equipment such as high-intensity-discharge lamps for automobile headlamps, servo-motor drives, $\mathrm{X}$-ray power generators, computer periphery power supplies, and uninterruptible power supplies [4]. To achieve high voltage gains, classical boost and buckboost converters require large switch duty ratios. The maximum voltage gain that can be achieved is constrained by the parasitic resistive components in the circuit and the efficiency is drastically reduced for large duty ratios. Also, larger ripples on the high input current and output voltage would further degrade the efficiency of the converter [5].

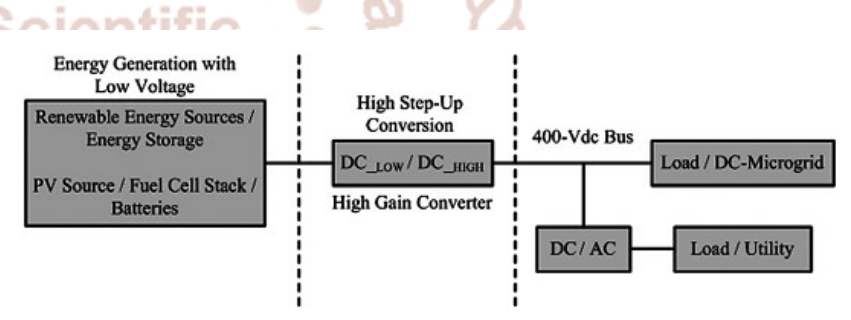

Fig. 1. High-voltage-gain dc-dc converter in de microgrid system.

Typically high-frequency transformers or coupled inductors are used to achieve high-voltage conversion ratios [6]-[15]. The transformer design is complicated and the leakage inductances increase for achieving larger gains, as it requires higher number of winding turns. This leads to voltage spikes across the switches and voltage clamping techniques are required to limit voltage stresses on the switches. To achieve highvoltage conversion ratios, a new family of highvoltage-gain dc-dc power electronic converters has been introduced. This converter can be used to draw power from two dc sources as a multiport converter [16], [17]. They draw continuous input current from both the input sources with low current ripple which is required in many applications, e.g., solar. In 
conventional approaches, as the output voltage of PV panel is low, several panels are connected in series when connecting the PV array to the $400-\mathrm{V}$ dc bus through conventional step-up converters. This results in reduced system reliability which can be addressed by connecting high-voltage-gain converter to each individual PV panel.Similar converters with interleaved boost input have been proposed earlier using the Cockcroft-Walton $(\mathrm{CW})$ voltage multiplier (VM) [18], [19]. Current fed converters are superior in comparison to the voltage fed counterparts as they have lower input current ripple [19]. The demerit with the $\mathrm{CW}$-based converters is that the output impedance increases rapidly with the number of multiplying stages [20].

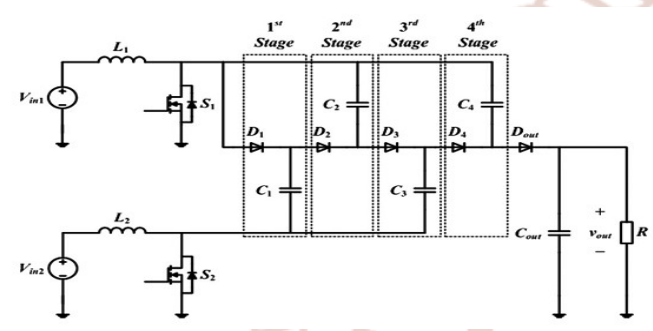

Fig. 2. Proposed high-voltage-gain dc-dc converter with four VM stages.

\section{MODES OF OPERATION OF CONVERTER}

The proposed converter is inspired from a Dickson charge pump [20]. Diode-capacitor VM stages are integrated with two boost stages at input. To help the boost stage VM stages are used achieve a higher overall voltage gain. The voltage conversion ratio depends on the number of VM stages and the switch duty ratios of the input boost stages. Fig. 2 shows the proposed converter with four VM stages. For better understanding, the converter operation with four multiplier stages has been explained here. For normal operation of the proposed converter, there should be some overlapping time when both the switches are $\mathrm{ON}$ and also one of the switches should be $\mathrm{ON}$ at any given time (see Fig. 3). Therefore, the converter has three modes of operation. The proposed converter can operate when the switch duty ratios are small and there is no overlap time between the conduction of the switches. However, this mode of operation is not of interest as it leads to smaller voltage gains.

\section{A. Mode-I}

In this mode, both the switches $\mathrm{S} 1$ andS2 are ON. Both the inductors are charged from input sources
Vin1 andVin2. The current in both the inductors rise linearly. The

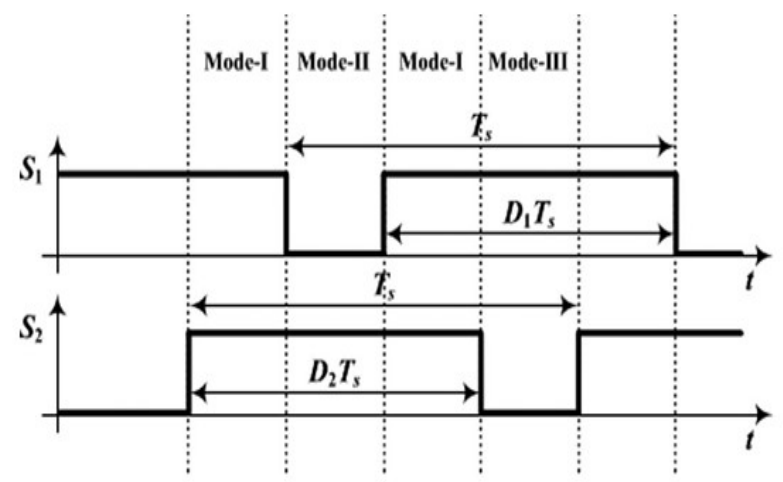

Fig. 3. Switching signals for the input boost stage for the proposed converter

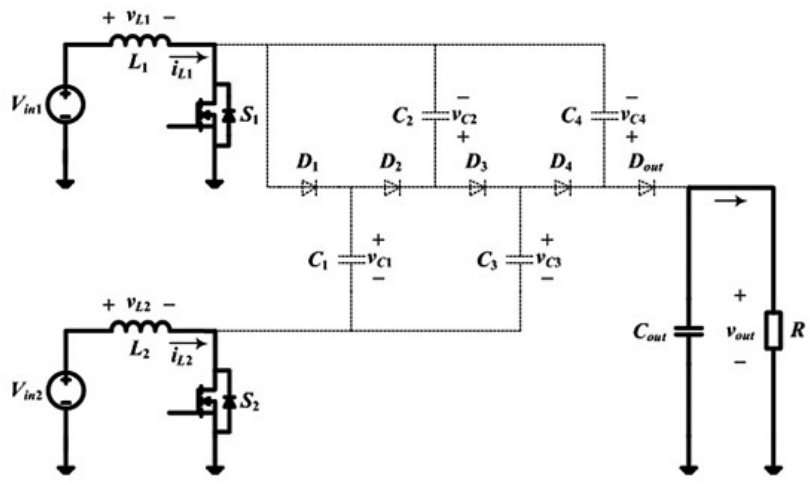

Fig. 4. Mode-I of operation for the proposed converter with four VM stages.

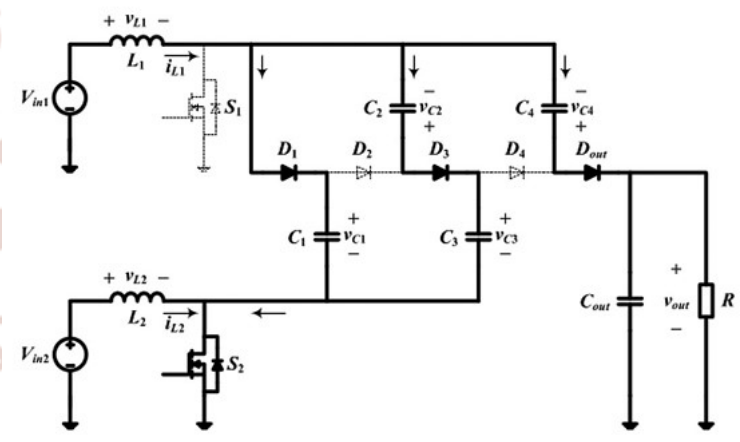

Fig. 5. Mode-II of operation for the proposed converter with four VM stages.

VM capacitor voltages remain unchanged and the output diode $\mathrm{D}_{\text {out }}$ is reverse biased (see Fig. 4); thus, the load is supplied by the output capacitor $\mathrm{C}_{\text {out }}$.

\section{B. Mode-II}

In this mode, the switch $\mathrm{S} 1$ is $\mathrm{OFF}$ and $\mathrm{S} 2$ is $\mathrm{ON}$ (see Fig. 5). All the odd numbered diodes are forward biased and the inductor currentIL1 flows through the 
VM capacitors charging the odd numbered capacitors $(\mathrm{C} 1, \mathrm{C} 3, \ldots)$ and discharging the even numbered capacitors(C2,C4, However, if the number of VM stages is even, then the output diode is forward biased charging the output capacitor and supplying the load.

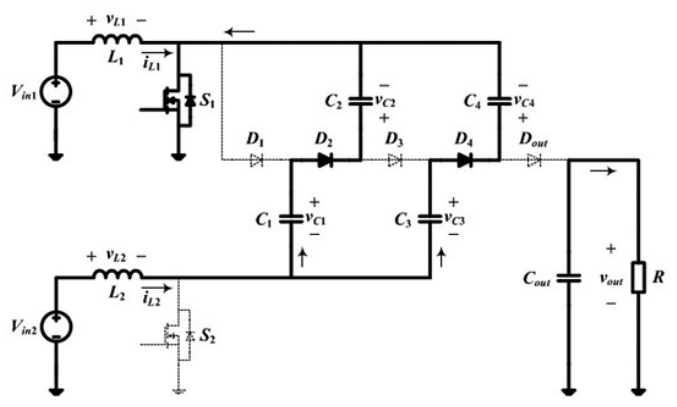

Fig. 6. Mode-III of operation for the proposed converter with four VM stages.

According to, case considered here, since there are four VM stages, the output diode in forward biased.

\section{Mode-III}

In this mode, switch $\mathrm{S} 1$ is $\mathrm{ON}$ and $\mathrm{S} 2$ is OFF (see Fig. 6). Now, the even numbered diodes are forward biased and the inductor current $\mathrm{I}_{\mathrm{L} 2}$ flows through the VM capacitors charging the even numbered capacitors and discharging the odd numbered capacitor. However, if the number of VM stages is even, then the output diode is reverse biased and the load is supplied by the output capacitor.

\section{VOLTAGE GAIN OF THE CONVERTER}

The charge is transferred progressively from input to the output by charging the VM stage capacitors. For the converter with four stages of VM (see Fig. 2), the voltage gain can derived from the volt-sec balance of the boost inductors. For L1, one can write

$$
\left\langle v_{L 1}\right\rangle=0 .
$$

Therefore, from Fig. 5, it can observed that the capacitor voltages can be written in terms of upper boost switching node voltage as

$$
V_{C 1}=V_{C 3}-V_{C 2}=V_{\text {out }}-V_{C 4}=\frac{V_{\text {in1 }}}{\left(1-d_{1}\right)}
$$

When d1is switching duty cycle forS1. Similarly, from the volt-sec balance of the lower leg boost
inductorL2, one can write the capacitor voltages (see Fig. 6) in terms of lower boost switching node voltage

$$
V_{C 2}-V_{C 1}=V_{C 4}-V_{C 3}=\frac{V_{\text {in2 }}}{\left(1-d_{2}\right)}
$$

Where $\mathrm{d} 2$ is the switching duty cycle for S2. From (2) and (3), the capacitor voltages for the proposed converter with four VM stages can be derived

$$
V_{C 1}=\frac{V_{\text {in1 }}}{\left(1-d_{1}\right)}
$$

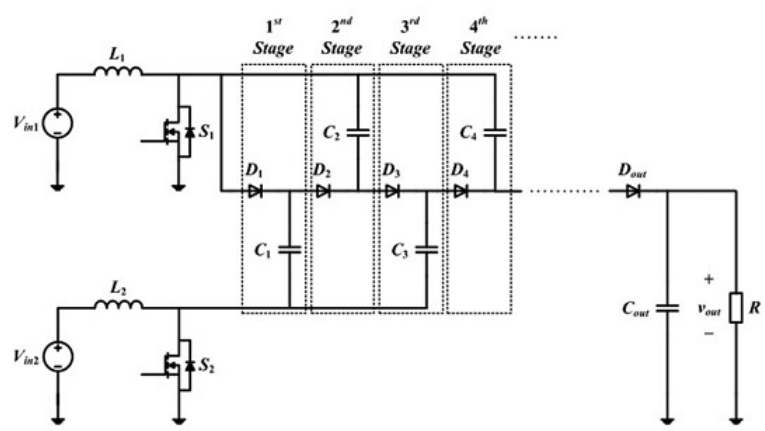

Fig. 7. Proposed converter with $\mathrm{N}$ number of VM stages.

$$
\begin{aligned}
& V_{C 2}=\frac{V_{\mathrm{in} 1}}{\left(1-d_{1}\right)}+\frac{V_{\mathrm{in} 2}}{\left(1-d_{2}\right)} \\
& V_{C 3}=\frac{2 V_{\mathrm{in} 1}}{\left(1-d_{1}\right)}+\frac{V_{\mathrm{in} 2}}{\left(1-d_{2}\right)} \\
& V_{C 4}=\frac{2 V_{\mathrm{in} 1}}{\left(1-d_{1}\right)}+\frac{2 V_{\mathrm{in} 2}}{\left(1-d_{2}\right)} .
\end{aligned}
$$

The output voltage is derived from (2), which is given by

$$
V_{\text {out }}=V_{C 4}+\frac{V_{\text {in1 }}}{\left(1-d_{1}\right)}=\frac{3 V_{\text {in } 1}}{\left(1-d_{1}\right)}+\frac{2 V_{\text {in2 }}}{\left(1-d_{2}\right)} .
$$

Similar analysis can be extended to a converter with $\mathrm{N}$ number of VM stages (see Fig. 7). Thus, the VM stage capacitor voltages are given by

$$
\begin{aligned}
V_{C n}= & \left(\frac{n+1}{2}\right) \frac{V_{\mathrm{in} 1}}{\left(1-d_{1}\right)}+\left(\frac{n-1}{2}\right) \frac{V_{\mathrm{in} 2}}{\left(1-d_{2}\right)} \\
& \text { if } n \text { is odd \& } n \leq N, \\
V_{C n}= & \left(\frac{n}{2}\right) \frac{V_{\mathrm{in} 1}}{\left(1-d_{1}\right)}+\left(\frac{n}{2}\right) \frac{V_{\mathrm{in} 2}}{\left(1-d_{2}\right)} \\
& \text { if } n \text { is even \& } n \leq N .
\end{aligned}
$$


The output voltage equation of the converter with $\mathrm{N}$ number of VM stages depends on whether $\mathrm{N}$ is odd or even and is given by

$$
\begin{aligned}
V_{\text {out }} & =V_{C N}+\frac{V_{\text {in2 }}}{\left(1-d_{2}\right)} \quad \text { if } N \text { is odd } \\
& =\left(\frac{N+1}{2}\right) \frac{V_{\text {in } 1}}{\left(1-d_{1}\right)}+\left(\frac{N+1}{2}\right) \frac{V_{\text {in } 2}}{\left(1-d_{2}\right)} \\
V_{\text {out }} & =V_{C N}+\frac{V_{\text {in } 1}}{\left(1-d_{1}\right)} \quad \text { if } N \text { is even } \\
& =\left(\frac{N+2}{2}\right) \frac{V_{\text {in } 1}}{\left(1-d_{1}\right)}+\left(\frac{N}{2}\right) \frac{V_{\text {in } 2}}{\left(1-d_{2}\right)} .
\end{aligned}
$$

When converter operates in an interleaved manner with single input source, ifd 1 andd 2 are choosen to be an identical, i.e., $\mathrm{d} 1=\mathrm{d} 2=\mathrm{d}$, then the output voltage is given by

$$
V_{\text {out }}=(N+1) \frac{V_{\text {in }}}{(1-d)} .
$$

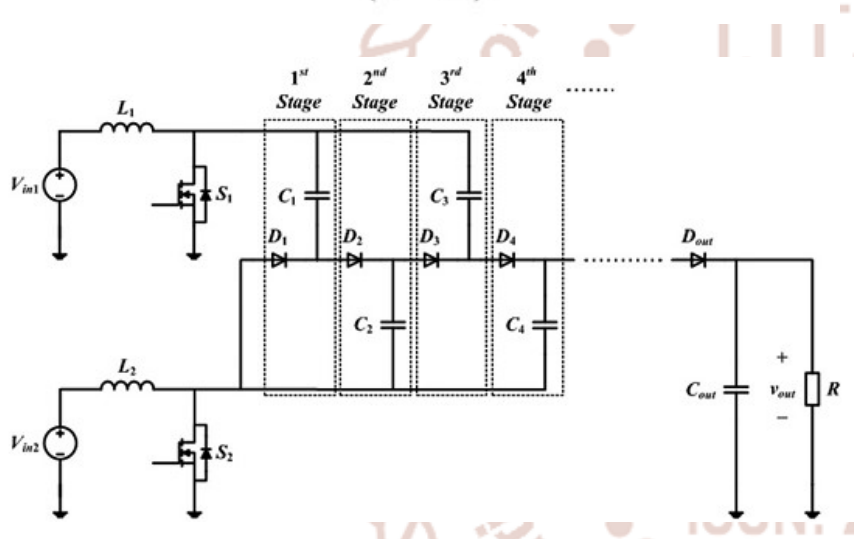

Fig. 8. Alternative to the proposed converter with N number of VM stages.

In [21], an interleaved boost power factor corrected converter with voltage-doubler characteristics is introduced. It is worth noting that there is an alternative to the proposed converter (see Fig. 8) where diodeD1 of the first VM stage is connected to the lower boost switching node and capacitorC1 is connected to the upper boost switching node (compare with Fig. 7). The output voltage equation for this alternative topology is given by

$$
\begin{aligned}
V_{\text {out }}= & \left(\frac{N+1}{2}\right) \frac{V_{\text {in } 1}}{\left(1-d_{1}\right)}+\left(\frac{N+1}{2}\right) \frac{V_{\text {in } 2}}{\left(1-d_{2}\right)} \\
& \text { if } N \text { is odd } \\
V_{\text {out }}= & \left(\frac{N}{2}\right) \frac{V_{\text {in } 1}}{\left(1-d_{1}\right)}+\left(\frac{N+2}{2}\right) \frac{V_{\text {in } 2}}{\left(1-d_{2}\right)}
\end{aligned}
$$$$
\text { if } N \text { is even. }
$$

For $\mathrm{N}=1$, if one combines the topology depicted in Fig. 7 with its alternative (see Fig. 8), then the resulting converter in Fig. 9 is similar to the multiphase converter introduced in [22]. When both topologies with $\mathrm{N}$ number of $\mathrm{VM}$ stages are combined, the finalised converter is shown in Fig. 10. When $\mathrm{N}$ is odd, then from (7) and (10), the voltage gain of the combined topology is given by

$$
V_{\text {out }}=\left(\frac{N+1}{2}\right) \frac{V_{\text {in } 1}}{\left(1-d_{1}\right)}+\left(\frac{N+1}{2}\right) \frac{V_{\text {in2 }}}{\left(1-d_{2}\right)}
$$

if $N$ is odd.

In this case, the original topology and its alternative each process half of the output power. In other words, the average currents ofDoutlandDout2are equal. When $\mathrm{N}$ is even, the output voltage of the combined topology would be either (8) or (11) and will be dictated by the topology that provides a higher output voltage. Both legs (see Fig. 10) would compete with each other and only one of the output diodes (DoutlandDout2) would process the entire power while the other will be reverse biased. When Nis even, putting the converters in parallel only makes sense if there is only one source used and $\mathrm{d} 1=\mathrm{d} 2$.
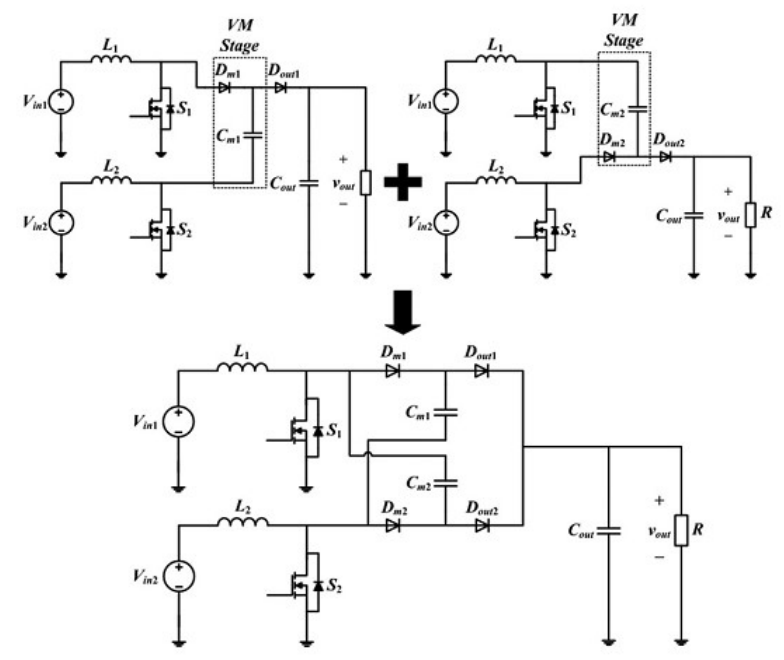

Fig. 9. Combined topology with single VM stage.

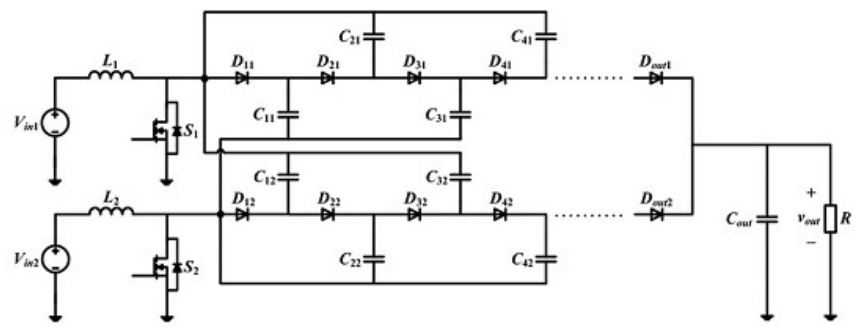

Fig. 10. Combined topology with Number of VM stages. 
output voltage to be

$$
V_{\text {out }}=(N+1) \frac{V_{\text {in }}}{(1-d)} \quad \text { if } N \text { is even. }
$$

For the combined topology with a single input source and identical duty ratiosd 1 andd2, i.e., $\mathrm{d} 1=\mathrm{d} 2=\mathrm{d}$, both the boost stages will always have symmetrical inductor and switch currents irrespective of the number of VM stages.

\section{IV.SIMULATION RESULTS}

The proposed dc-dc high gain with two input stages for pv systems performance is studied in MATLAB/SIMULINK platform. The fig 11 shows the simulated circuit of dc-dc high gain converter and control circuit. The continuous current of two input inductors are shown in fig 12, the output voltage of converter in fig 13. The performance of proposed converter is also analyzed by using it in photovoltaic systems. It is observed that the gain of the converter attains 20. The simulation diagrams of photovoltaic panel and the output current and voltage are also presented.

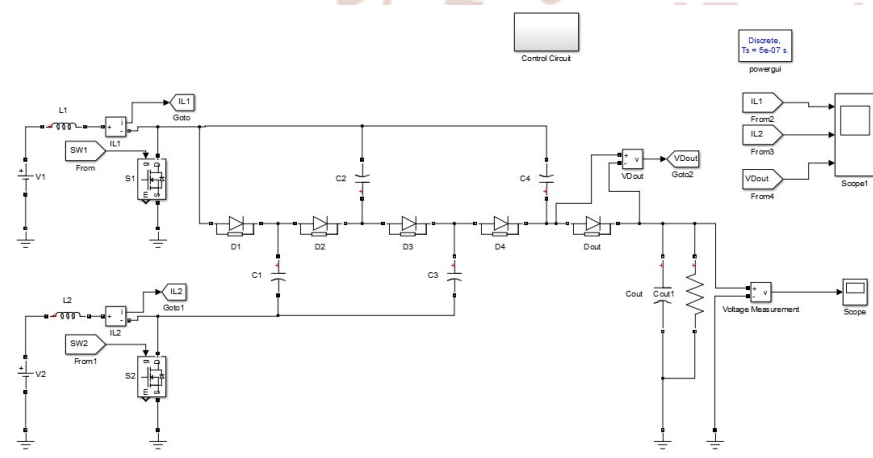

Fig 11. Simulation diagram of DC-DC High Gain Converter
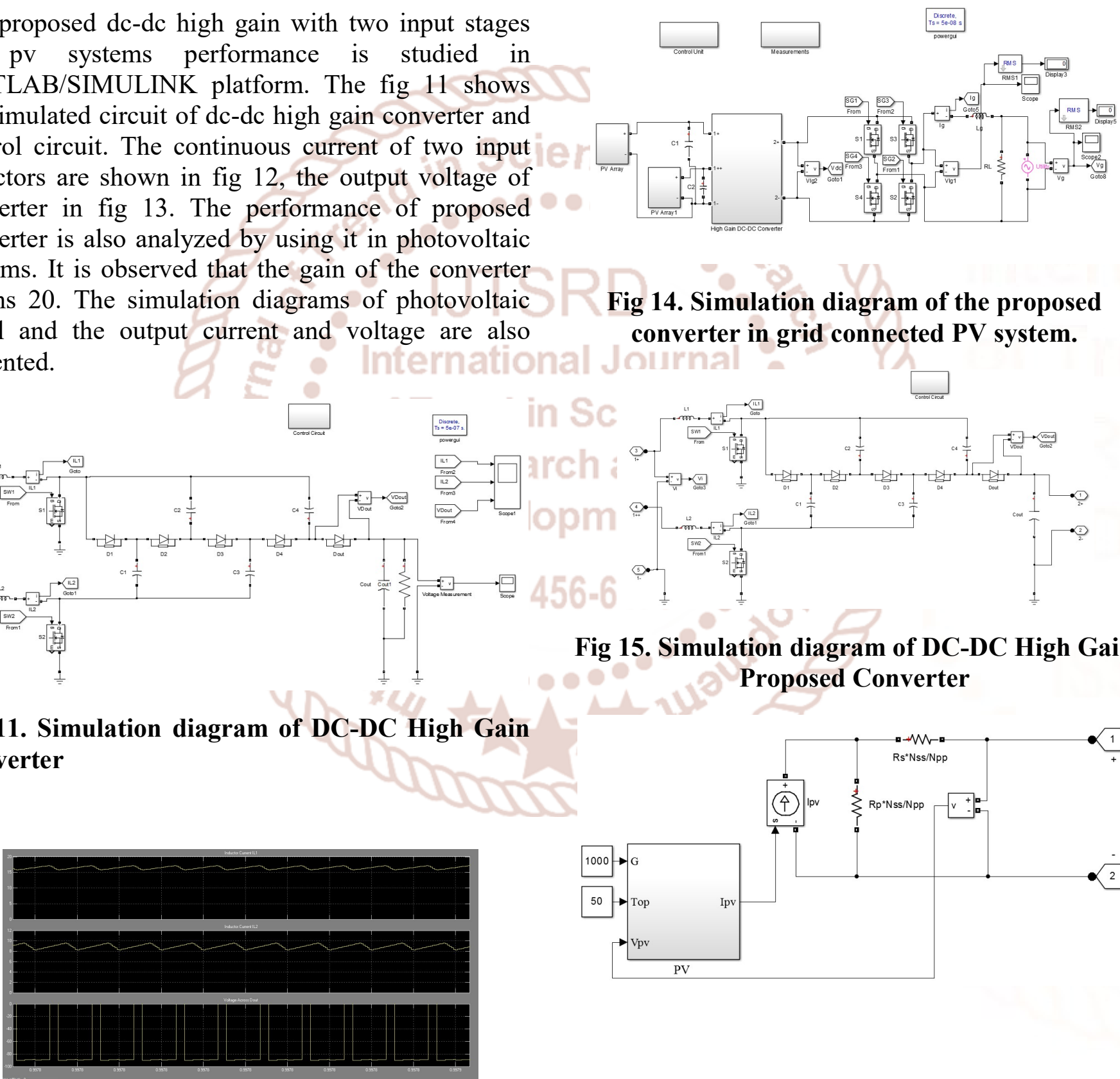

Fig 14. Simulation diagram of the proposed converter in grid connected PV system.

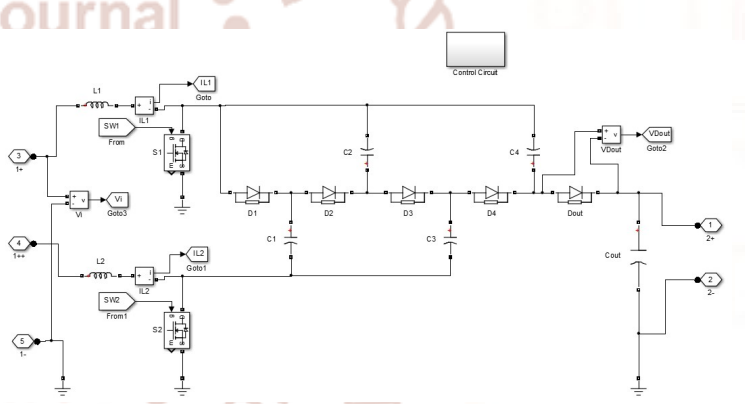

Fig 15. Simulation diagram of DC-DC High Gain Proposed Converter

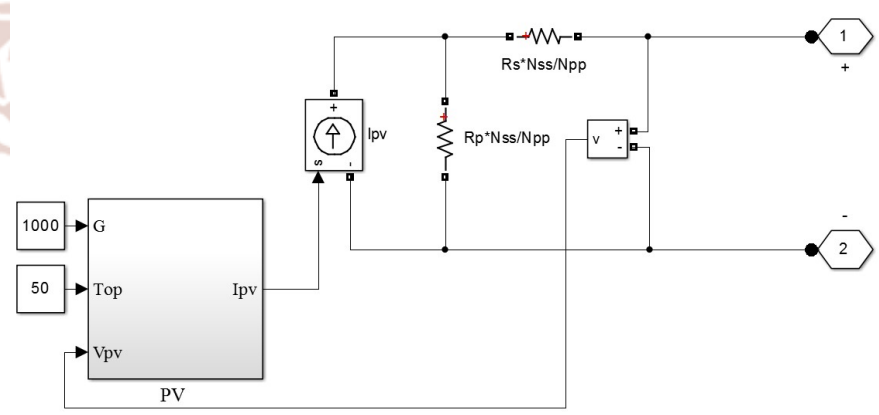

Fig 12. Two Input Inductor continuous currents and voltage across Dout. 


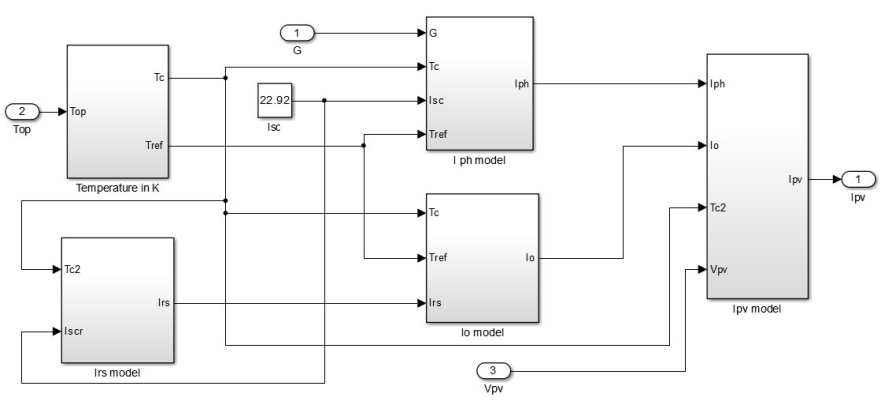

Fig 16\&17. Modeling of PV panel

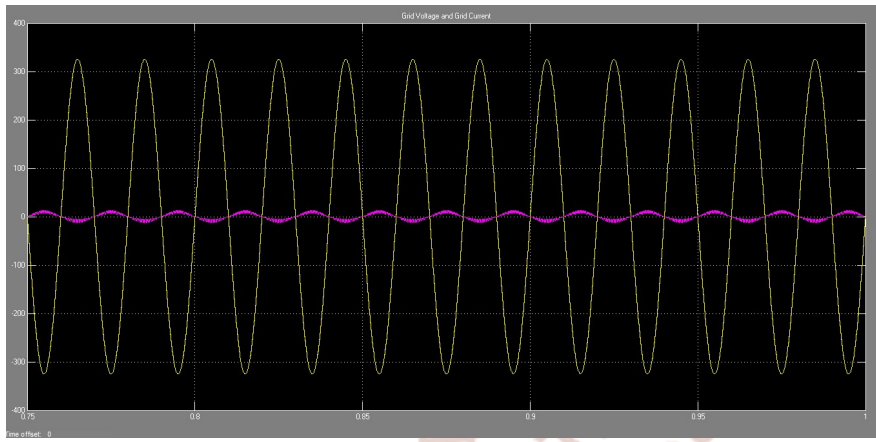

Fig 18. Grid voltage and grid current.

\section{CONCLUSION}

In this paper, a family of novel high-voltage-gain dcdc converters with two boost stages at the input for photovoltaic applications has been proposed. The proposed converter is based on diode-capacitor VM stages and the voltage gain is increased by increasing the number of VM stages. Power can be drawn from two input sources like a multiport converter in an interleaved manner when connected to single source. One of the advantages of the proposed converter is that since it is a multiport converter with high voltage gain, it has the flexibility to be connected to independent sources while allowing power sharing, MPPT algorithms, etc., to be implemented independently at each input port. Furthermore, an alternative topology of the proposed converter has been presented and combining them both would result in a new converter topology. The proposed converter can be used for solar applications where each panel can be individually linked to the $400-\mathrm{V}$ dc bus.

\section{REFERENCES}

1) S. Jain and V. Agarwal, "A single-stage grid connected inverter topology for solar PV systems with maximum power point tracking,'IEEE Trans. Power Electron., vol. 22, no. 5, pp. 1928-1940, Sep. 2007.

2) X. Kong and A. M. Khambadkone, "Analysis and implementation of a high efficiency, interleaved current-fed full bridge converter for fuel cell system,'IEEE Trans. Power Electron., vol. 22, no. 2, pp. 543-550, Mar. 2007.

3) C. Liu and J. S. Lai, "Low frequency current ripple reduction technique with active control in a fuel cell power system with inverter load,"IEEE Trans. Power Electron., vol. 22, no. 4, pp. 14291436, Jul. 2007.

4) E. H. Ismail, M. A. Al-Saffar, A. J. Sabzali, and A. A. Fardoun, "A family of single-switch PWM converters with high step-up conversion ratio," IEEE Trans. Circuits Syst. I, Reg. Papers, vol. 55, no. 4, pp. 1159-1171, May 2008.

5) R. W. Erickson and D. Maksimovic, Fundamentals of Power Electronics, 2nd ed. Norwell, MA, USA: Kluwer, 2001.

6) W. Li and X. He, "A family of interleaved DCDC converters deduced from a basic cell with winding-cross-coupled inductors (WCCIs) for high step-up or step-down conversions,"IEEE Trans. Power Electron., vol. 23, no. 4, pp. 17911801, Jul. 2008.

7) W. Li and X. He, "An interleaved windingcoupled boost converter with passive lossless clamp circuits,'IEEE Trans. Power Electron., vol. 22, no. 4, pp. 1499-1507, Jul. 2007.

8) W. Li, Y. Zhao, Y. Deng, and X. He, "Interleaved converter with voltage multiplier cell for high step-up and high-efficiency conversion,'IEEE Trans. Power Electron., vol. 25, no. 9, pp. 23972408, Sep. 2010.

9) Y.-P. Hsieh, J.-F. Chen, T.-J. Liang, and L.-S. Yang, "A novel high step-up DC-DC converter for a microgrid system,"IEEE Trans. Power Electron., vol. 26, no. 4, pp. 1127-1136, Apr. 2011.

10) R. Xie, W. Li, Y. Zhao, J. Zhao, X. He, and F. Cao, "Performance analysis of isolated ZVT interleaved converter with winding-cross-coupled inductors and switched-capacitors," in Proc. IEEE Energy Convers. Congr. Expo., Atlanta, GA, USA, 2010, pp. 2025-2029.

11) W. Li, W. Li, X. He, D. Xu, and B. Wu, "General derivation law of nonisolated high-step-up interleaved converters with built-in transformer,"IEEE Trans. Ind. Electron., vol. 59, no. 3, pp. 1650-1661, Mar. 2012. 
12) K.-C. Tseng, C.-C. Huang, and W.-Y. Shih, "A high step-up converter with a voltage multiplier module for a photovoltaic system,'IEEE Trans. Power Electron., vol. 28, no. 6, pp. 3047-3057, Jun. 2013.

13) W. Li, Y. Zhao, J. Wu, and X. He, "Interleaved high step-up converter with winding-crosscoupled inductors and voltage multiplier cells,"IEEE Trans. Power Electron., vol. 27, no. 1, pp. 133-143, Jan. 2012.
14) K.-C. Tseng and C.-C. Huang, "High step-up high-efficiency interleaved converter with voltage multiplier module for renewable energy system," IEEE Trans. Ind. Electron., vol. 61, no. 3, pp. 1311-1319, Mar. 2014.

15) K.-C. Tseng and C.-C. Huang, "A high step-up passive absorption circuit used in non-isolated high step-up converter," inProc. IEEE Appl. Power Electron. Conf. Expo., Long Beach, CA, USA, 2013, pp. 1966-1971.

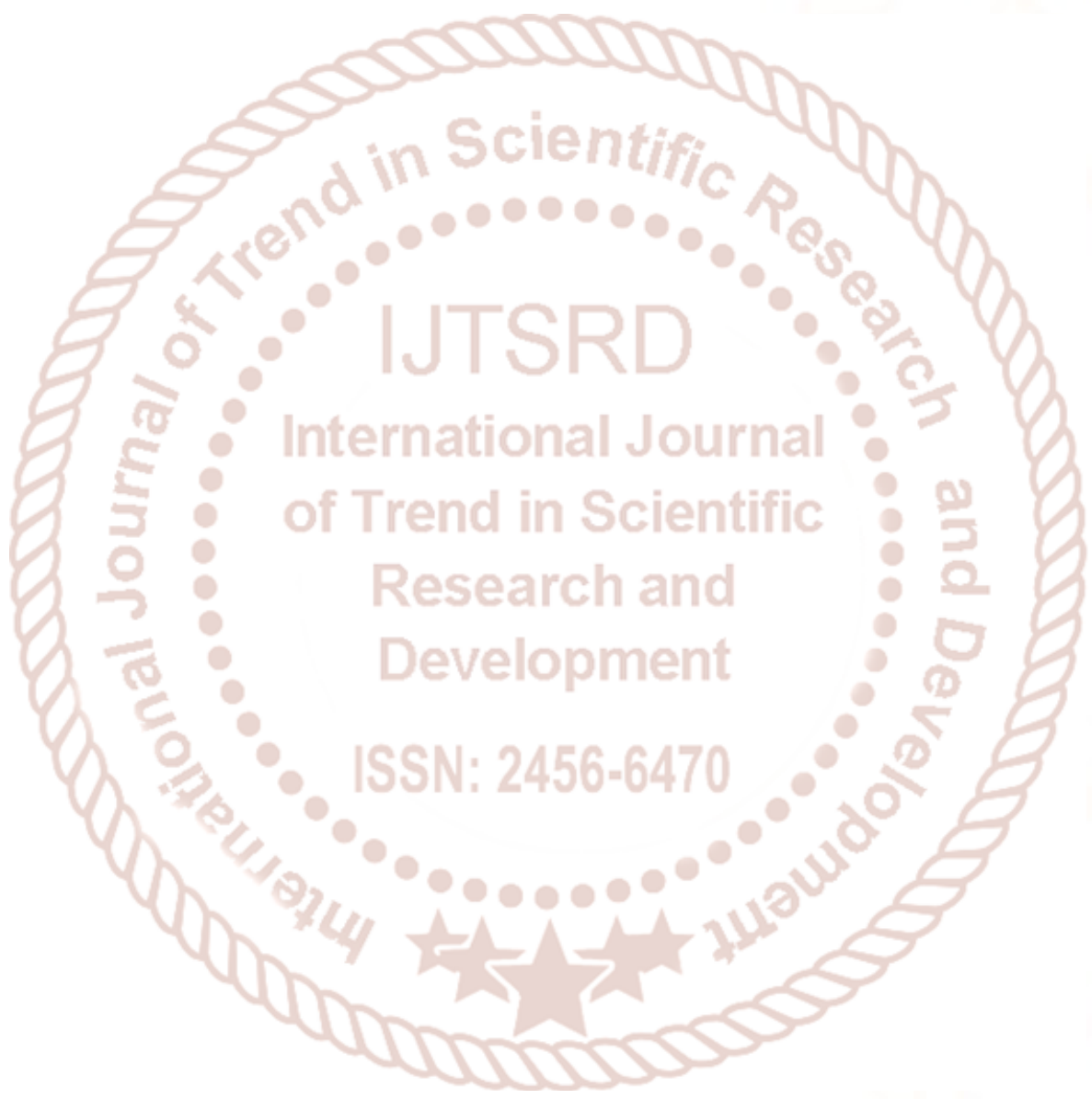

